\title{
EFFECTS OF FLEXION-EXTENSION MOVEMENTS OF THE HEAD AND SPINE UPON THE SPINAL CORD AND NERVE ROOTS
}

BY

\author{
J. D. REID \\ From the Pathology Department, Wellington Hospital, Wellington, New Zealand
}

In a series of dissections of the spinal cord it was noticed that the cord, dura, and nerve roots moved up and down within the spinal canal on flexing or extending the head and neck. In certain sections these changes appeared to be more marked than in others. In flexion, the length of the canal was increased and the cord and dura were stretched, with an increase over their normal tensions.

Where stretch was exerted over a convexity, as normally in the thoracic spine, or in the neck after conversion of the normal lordosis to a flexion kyphosis, it appeared that there must be a considerable component of force directed anteriorly and holding the cord against the ventral wall of the canal. These changes of movement, stretch and tension seemed likely to have general importance as factors aggravating various pathological processes, and this paper records the results of an investigation into their extent in different sections of the cord, and a consideration of their possible significance, particularly in cervical spondylosis. In this condition, one of the features to which attention has been called by a number of workers (Taylor, 1953; O'Connell, 1956; Logue, 1957; Bradshaw, 1957) is the discrepancy which may exist between the severity of signs and symptoms and the minor nature of protrusions into the canal or lack of evidence of cord compression. Several explanations have been offered, all describing mechanical means whereby the cord may be forced into contact with any protrusions present. These include various causes of narrowing of the canal, or of tethering of the cord in an anterior position. While exploring the significance of movement and tension of the dura and cord in this respect, the opportunity was taken to examine some of these previously described mechanisms.

\section{Materials and Methods}

The terminology used has been defined previously (Reid, 1960). Subjects have been routine necropsy cases

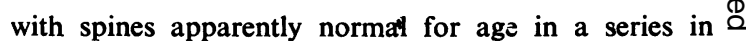
which the direction of nerve roots was being examined. ڤ The numbers of cases used in different investigations, $\overrightarrow{0}$ with their age and sex distribution, are given separately in tables of results. Dissections were made as previously described. Measurements were made between small $\stackrel{\omega}{\rho}$ upholsterer's nails or pins driven into the bone of the pedicles, and similar pins inserted through the intact dura into the cord. Calipers were used over curvatures is but where access was free and the cord straight a ruler $\omega$ was employed. No attempt to measure in less than $i$ millimetres was felt justifiable. Pins in the cord we placed opposite nerve roots and consequently the cora segments implicated were one or two lower than the number of the root. For flexion of the head and neck the prone body was moved up the table until the chin could be approximated to the chest. In flexing the trung

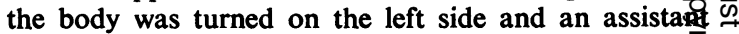
held the legs and head in a flexed posture with the kne $\overrightarrow{0}$ bent. The effects of rigor mortis could not altogether avoided but were lessened by forcible flexion. With adult cadavers, however, it was clear that the degree of flexion produced in the spine varied from individual to individual, depending on ante-mortem mobility of the spine, on rigor, and on flexion force applied. It also tended to vary somewhat in repeated observations on the same subject.

The effects of removing spines and muscles were considered and thought of no practical significance, since the movements being produced were not beyond the normal range and joints remained intact. In two cases, measurements made after exposure by unilateral laminectomy were repeated after full exposure of the canal. No significant differences were found.

Measurements of the pressure exerted between the $\frac{5}{3}$ cord and the canal were made in three apparently normal: subjects aged 7,18 , and 33 years respectively. The body was supported on its left side and a thin, curved $₹$ metal strip, $4 \mathrm{~mm}$. in width, was passed in front of $\mathrm{O}$ the dura as a hook. From this a string was run horizontally at right angles to the cord over a pulley on ao stand at the side of the necropsy table to a measuring pan. Weights were added to the pan until the cord was $N$ moved $3 \mathrm{~mm}$. out of its bed as measured by movement of the pulley. The force required to do this was assumed 
to be the same in degree as that which would be exerted against a $3 \mathrm{~mm}$. protrusion if such were displacing the cord dorsally.

Other mechanisms said to hold the cord against the anterior wall of the canal were investigated both with unilateral and more often bilateral laminectomy. The dura and cord were lifted from the anterior wall of the canal by a narrow dissector, with the spine in various positions of flexion. A longitudinal slit was made in the dura just posterior to the dorsal roots, and dorsal displacement of the cord within the dural sac could be examined in its effect on rootlets and ligamenta denticulata, as well as on roots.

\section{Relation of Cord to Dura Mater}

Because opening of the dura clearly altered the stresses on the cord, it seemed necessary to examine their movements together and with the dura intact and closed. Except in the upper cervical region, where deviation occurred, pins inserted at right angles to the surface of the dura and into the cord showed no angulation with flexion extension movements, as would have been expected had the dura changed its position relative to the cord. The reason why cord and dura moved together appeared to lie in the number and nature of the ligamenta denticulata. These have a broad base of origin at the cord, long free margins, and a narrow apical insertion at the dura so that any up-and-down movement of either cord or dura is quickly transmitted one to the other. Cephalic traction on the dura, slackening rootlets, was found to be equally as effective in moving the cord as was caudal traction. Pull on nerve roots transmitted its effects to the cord via the dural sheath and the ligamenta denticulata rather than the rootlets. Below the midcervical region it appeared valid to measure up-and-down movements of the cord from pins inserted through the closed intact dura.
Movements of Cord and Dura on Flexion-extension of the Head and Neck and on Flexion of Head, Neck, and Trunk

Results are given in Table I. Considerable difficulty was experienced in measurements in the upper cervical region, particularly in extension when the head tended to cover the field. Since results in any case were not thought reliable because of angulation of pins, no values are offered. At C5 there was virtually no movement in extension but sometimes a millimetre of cephalic shift in flexion; there was no observable movement in flexion in four of seven cases. At levels of roots C8 to T3 considerable movement took place both in flexion and in extension, with a total range of movement up to $1.8 \mathrm{~cm}$. (Figs. 1 and 2). Flexion of the trunk as well as of the head and neck made no appreciable difference except in lower levels, and at T12 there was downward rather than upward movement of a few millimetres. In extension, maximum movement occurred opposite roots $\mathrm{C} 8$ to $\mathrm{Tl}$ and was in a downward direction.

\section{Stretch, Tension, and Component of Force Acting Anteriorly}

Both cord and dura have a natural elasticity which may be roughly estimated when the spinal canal is unroofed by gauging the distance by which the dura and cord may be freely lifted dorsally and also by estimating the extent of their free movement in an up-and-down direction. The degree of tension varies considerably from case to case. A dorsal lift of about $1 \mathrm{~cm}$. or an up-and-down movement of similar value can be found at T5 in one-third of cases. In some, particularly in the aged, the entire dura appears crinkled and slack, and in still others it appears rather tight. As was well shown by O'Connell (1956), when flexion of the head and

TABLE I

MOVEMENTS OF DURA AND CORD RELATIVE TO SPINAL CANAL IN FLEXION-EXTENSION MOVEMENTS

\begin{tabular}{|c|c|c|c|c|c|c|c|c|c|c|c|c|}
\hline \multirow{3}{*}{ Root Level } & \multicolumn{3}{|c|}{$\begin{array}{c}\text { Flexion } \\
\text { Head and Neck }\end{array}$} & \multicolumn{3}{|c|}{$\begin{array}{c}\text { Flexion } \\
\text { Neck and Trunk }\end{array}$} & \multicolumn{3}{|c|}{$\begin{array}{c}\text { Extension } \\
\text { Head and Neck }\end{array}$} & \multicolumn{3}{|c|}{$\begin{array}{l}\text { Flexion-extension } \\
\text { Head and Neck }\end{array}$} \\
\hline & \multirow{2}{*}{$\begin{array}{l}\text { No. of } \\
\text { Obser- } \\
\text { vations }\end{array}$} & \multicolumn{2}{|c|}{ Movement (mm.) } & \multirow{2}{*}{$\begin{array}{l}\text { No. of } \\
\text { Obser- } \\
\text { vations }\end{array}$} & \multicolumn{2}{|c|}{ Movement (mm.) } & \multirow{2}{*}{$\begin{array}{l}\text { No. of } \\
\text { Obser- } \\
\text { vations }\end{array}$} & \multicolumn{2}{|c|}{ Movement (mm.) } & \multirow{2}{*}{$\begin{array}{l}\text { No. of } \\
\text { Obser- } \\
\text { vations }\end{array}$} & \multicolumn{2}{|c|}{ Movement (mm.) } \\
\hline & & Range & Average & & Range & Average & & Range & Average & & Range & Average \\
\hline $\begin{array}{r}\text { C5 } \\
6 \\
8 \\
T 1 \\
3 \\
5 \\
10 \\
12\end{array}$ & $\begin{array}{l}7 \\
4 \\
2 \\
9 \\
6 \\
7 \\
8 \\
8 \\
6\end{array}$ & $\begin{array}{l}0-5 \\
1-5 \\
3-6 \\
3-12 \\
4-8 \\
3-8 \\
0-3 \\
0-2\end{array}$ & $\begin{array}{l}1 \cdot 5 \\
2.7 \\
4 \cdot 5 \\
6 \cdot 8 \\
6 \cdot 1 \\
4 \cdot 0 \\
1.7 \\
0.8\end{array}$ & $\begin{array}{l}6 \\
2 \\
5 \\
2 \\
6 \\
6 \\
6\end{array}$ & $\begin{array}{l}3-3 \downarrow \\
2-7 \\
5-8 \\
5-8 \\
2-6 \\
3 \uparrow-1 \downarrow \\
2 \uparrow-5 \downarrow\end{array}$ & $\begin{array}{l}0 \\
4.5 \\
6 \cdot 6 \\
6.5 \\
3 \cdot 7 \\
0.6 \\
0.6 \downarrow\end{array}$ & $\begin{array}{l}3 \\
1 \\
3 \\
3 \\
3 \\
-\end{array}$ & $\begin{array}{c}0-0 \\
\overline{-} \\
2 \downarrow-8 \downarrow \\
4 \overline{-0} \\
1 \downarrow-0 \\
-\end{array}$ & $\begin{array}{l}0 \\
5 \downarrow \\
4 \cdot 7 \downarrow \\
\frac{2 \downarrow}{0 \cdot 3 \downarrow} \\
-\end{array}$ & $\begin{array}{r}3 \\
4 \\
3 \\
3 \\
3 \\
-\end{array}$ & $\begin{array}{l}3-7 \\
\overline{8-10} \\
6-18 \\
\overline{5-8} \\
2-3 \\
-\end{array}$ & $\begin{array}{c}3 \cdot 3 \\
\overline{9 \cdot 0} \\
12 \cdot 7 \\
\overline{6 \cdot 6} \\
2 \cdot 3 \\
\end{array}$ \\
\hline
\end{tabular}

No. of subjects used, 18 


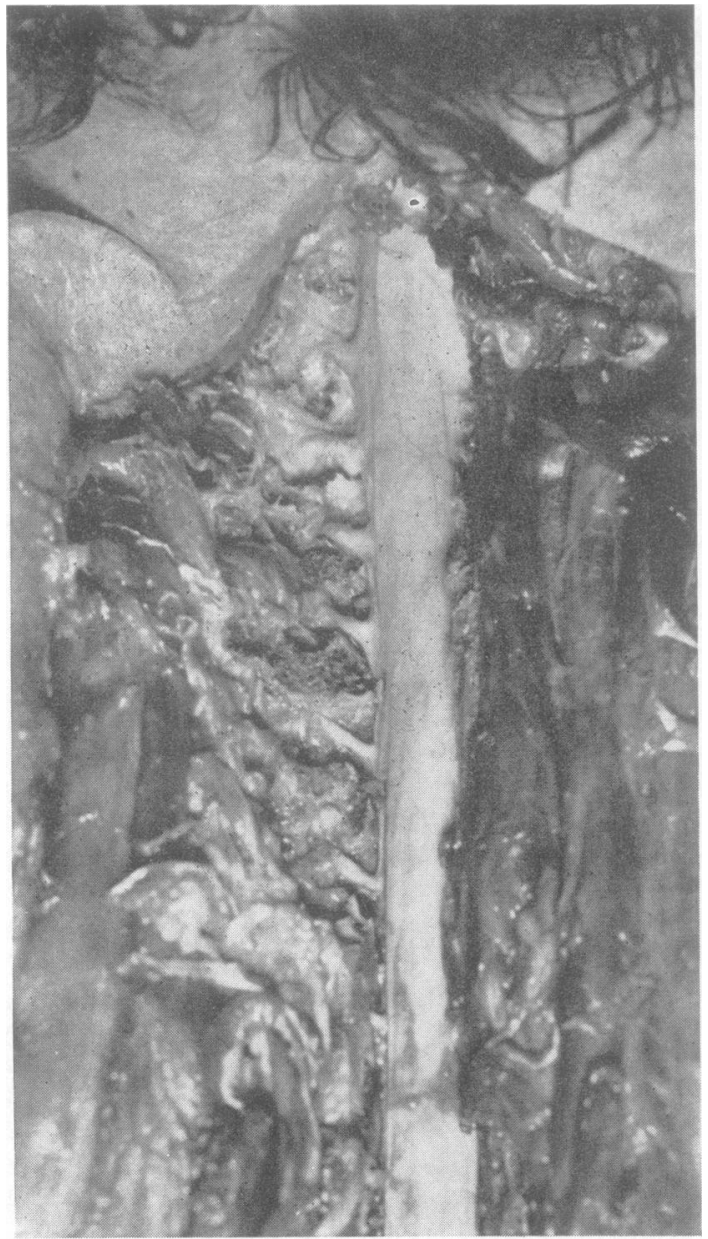

FIG. 1

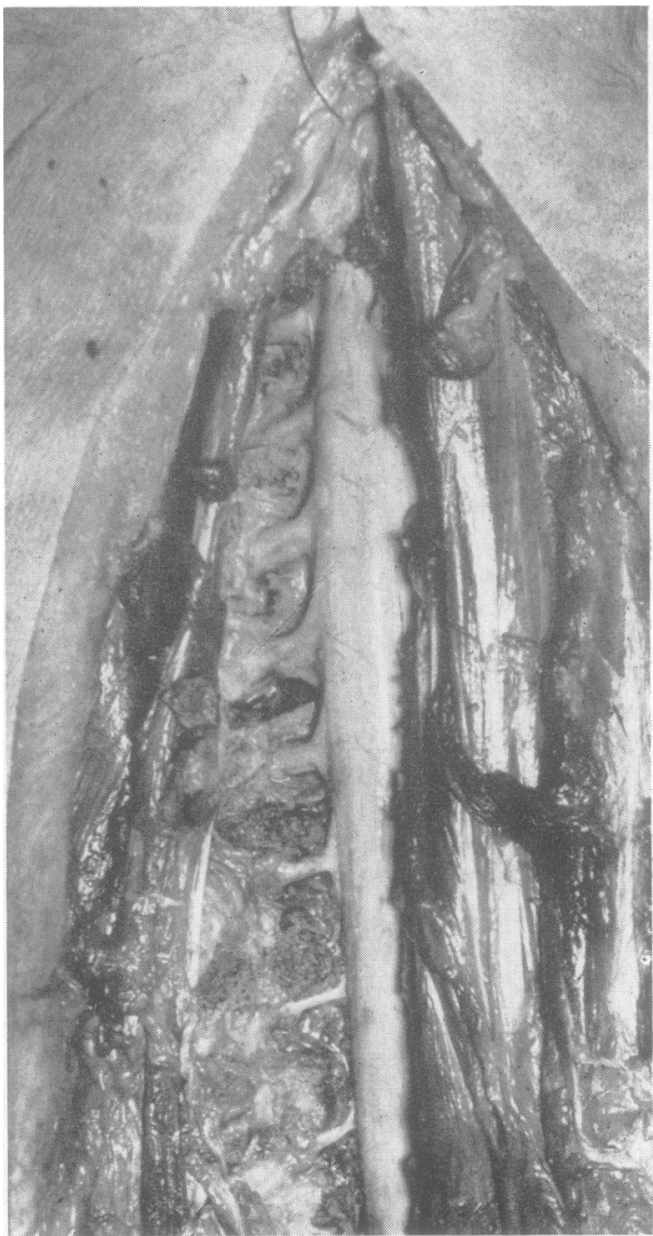

FIG. 2

FIGs. 1 and 2.-Case 54, F., 75 years.

The range of movement and change in direction of roots in extension (Fig. 1) and flexion (Fig. 2). In normal erect posture all roots ran downwards.

neck converts the cervical lordosis to a kyphosis, there is a considerable increase in length of the canal, particularly in its posterior wall. From the posterior margin of the foramen magnum to the level of the lower margin of the spine of the first dorsal vertebra this may be as much as $5 \mathrm{~cm}$. To compensate for this the dura and cord move cephalically as already shown, and at the same time stretch. Tension, however, is not equally distributed along their lengths. It has been observed not infrequently that the cervical dura in flexion may be quite taut while that in the thoracic region is still loose and wrinkled. This is presumably due to the tethering action of the loose fibrous tissue between the posterior common ligament and the anterior dura, and to a lesser extent to the nerve roots. The cervical dura and cord stretch much more than lower sections and the amount of stretch found at different levels is given in Table II. Results are comparable to those of a previous examination of four cases with the dura opened (Reid, 1958). In several cases measurements were first made between pins inserted opposite every nerve root. Since an increase in length of only $1 \mathrm{~mm}$. represented a $10 \%$ stretch in areas such as the neck where cord segments were only slightly more than $1 \mathrm{~cm}$. in length, it was necessary for accuracy to increase the length over which measurements 
TABLE II

STRETCH OF SPINAL CORD AND DURA ON FLEXION OF SPINE

\begin{tabular}{|c|c|c|c|c|c|c|c|}
\hline \multirow{2}{*}{ Root Intervals } & \multirow{2}{*}{$\begin{array}{c}\text { Segments } \\
\text { (approximate) }\end{array}$} & \multicolumn{3}{|c|}{ Flexion of Head and Neck } & \multicolumn{3}{|c|}{ Full Flexion } \\
\hline & & $\begin{array}{c}\text { No. of } \\
\text { Observations }\end{array}$ & Stretch $\%$ Range & Stretch $\%$ & $\begin{array}{c}\text { No. of } \\
\text { Observations }\end{array}$ & Stretch Range & Stretch $\stackrel{\%}{\%}$ Average \\
\hline $\begin{array}{l}\text { C2- } 5 \\
\text { C5- T1 } \\
\text { C6- T1 } \\
\text { T1- } 5 \\
\text { T5- } 10 \\
\text { T10- T12 }\end{array}$ & $\begin{array}{l}\text { C3- } 6 \\
\text { C6- T2 } \\
\text { T7- } 2 \\
\text { T2- } 7 \\
\text { T7- } 11 \\
\text { T11- L }\end{array}$ & $\begin{array}{l}3 \\
7 \\
3 \\
9 \\
6 \\
4\end{array}$ & $\begin{array}{l}7 \cdot 5-14 \cdot 7 \\
4 \cdot 2-17 \cdot 6 \\
5 \cdot 5-13 \cdot 6 \\
2 \cdot 0-6 \cdot 6 \\
0 \cdot 0-6 \cdot 4 \\
0 \cdot 0-3 \cdot 8\end{array}$ & $\begin{array}{r}10 \cdot 2 \\
9 \cdot 7 \\
9 \cdot 9 \\
4 \cdot 4 \\
2 \cdot 8 \\
2 \cdot 0\end{array}$ & $\begin{array}{l}3 \\
4 \\
4 \\
4 \\
4\end{array}$ & $\begin{array}{l}8 \cdot 2-15 \cdot 2 \\
4 \cdot 2-10 \cdot 1 \\
-1- \\
2 \cdot 1-8 \cdot 2 \\
2 \cdot 2-5 \cdot 4 \\
1 \cdot 7-5 \cdot 3\end{array}$ & $\begin{array}{c}11 \cdot 3 \\
7 \cdot 4 \\
\overline{5 \cdot 8} \\
3 \cdot 2 \\
3 \cdot 4\end{array}$ \\
\hline
\end{tabular}

Flexion of head and neck:

Number of subjects, 10. Ages $15-75$ years, average 38.5 years. Sex, 6 males, and 4 females

Flexion of head, neck, and trunk: Number of subjects, 4. Ages 15-40 years. Sex, 2 males, 2 females

TABLE III

FORCE REQUIRED TO LIFT SPINAL CORD $3 \mathrm{~mm}$. FROM ITS BED AT DIFFERENT LEVELS WITH CALCULATED PRESSURES

\begin{tabular}{|c|c|c|c|c|c|c|c|c|c|c|c|c|c|c|}
\hline \multirow{2}{*}{\multicolumn{3}{|c|}{$\begin{array}{l}\text { Case, Sex, } \\
\text { Age (yr.) }\end{array}$}} & \multicolumn{3}{|c|}{ C5-6 } & \multicolumn{3}{|c|}{ C7-8 } & \multicolumn{3}{|c|}{ T5-6 } & \multicolumn{3}{|c|}{ T11-12 } \\
\hline & & & N. (oz.) & F.N. (oz.) & F.N.T. & N. (oz.) & F.N. (oz.) & F.N.T. & N. (oz.) & F.N. (oz.) & F.N.T. & N. (oz.) & F.N. (oz.) & F.N.T \\
\hline 79 & $\mathbf{M}$ & 7 & $1 \frac{1}{2}$ & 12 & $\begin{array}{l}16 \mathrm{oz} . \\
16 \mathrm{lb} /\end{array}$ & - & - & - & $1 \frac{1}{2}$ & 32 & $\begin{array}{l}36 \mathrm{oz} . \\
36 \mathrm{lb} . /\end{array}$ & $1 \frac{1}{2}$ & 8 & $\begin{array}{l}40 \mathrm{oz} . \\
40 \mathrm{lb} . /\end{array}$ \\
\hline 80 & $\mathbf{F}$ & 18 & 3 & 28 & $\begin{array}{l}\text { sq. in. } \\
36 \mathrm{oz} \text {. } \\
25 \mathrm{lb} \text {. }\end{array}$ & - & - & - & 2 & 20 & $\begin{array}{l}\text { sq. in. } \\
56 \mathrm{oz} \text {. } \\
40 \mathrm{lb} \text {. }\end{array}$ & 2 & 11 & $\begin{array}{l}\text { sq. in. } \\
48 \mathrm{oz} \text {. } \\
34 \mathrm{lb} \text {. }\end{array}$ \\
\hline 82 & $\mathbf{M}$ & 33 & - & 24 & $\begin{array}{l}\text { sq. in. } \\
24 \mathrm{oz} . \\
17 \mathrm{lb} / \\
\text { sq. in. }\end{array}$ & 4 & 28 & $\begin{array}{l}40 \mathrm{oz} . \\
29 \mathrm{lb} . / \\
\text { sq. in. }\end{array}$ & 4 & 12 & $\begin{array}{l}\text { sq. in. } \\
20 \mathrm{oz} . \\
14 \mathrm{lb./} \\
\text { sq. in. }\end{array}$ & 4 & 8 & $\begin{array}{l}\text { sq. in. } \\
16 \mathrm{oz} . \\
11 \mathrm{lb} . \\
\text { sq. in. }\end{array}$ \\
\hline
\end{tabular}

N. = normal posture $\quad$ F.N. = flexion of head and neck

F.N.T. = flexion of neck and trunk

Calculations based on hook of $4 \mathrm{~mm}$. width and on diameter of adult cord, cervical $1.4 \mathrm{~cm} .$, thoracic $1.0 \mathrm{~cm}$.

were made to include several segments. The possibility of greater stretch by additional flexion of trunk and hips was investigated in four cases. Recognizing that the manual force applied was not certainly the same as that previously used and accepting results as a rough guide only, it seemed possible that under conditions of full flexion stretch was somewhat increased.

The pressure exerted by the cord against the anterior wall of the spinal canal clearly varied in different areas. In normal erect posture the dura and cord tended to lift out of the concavity of the cervical lordosis, as could be seen on unroofing the canal at dissection. They were held forward to a variable degree by adhesions to the posterior common ligament, particularly above the level of C5 where there was minimal sliding movement. Over the thoracic kyphus they were closely opposed to the anterior wall of the canal. The results of measurements of the anterior component of force exerted by the dura and cord at different levels and in different degrees of flexion of the spine, in three normal subjects, are given in Table III. Mechanical difficulties and the limitations of available techniques made these rather crude, but until more accurate measuring devices are available they are offered as 4 a rough indication of the magnitude of the forces at play. A movement of $3 \mathrm{~mm}$. was arbitrarily chosen as a value open to reasonably accurate measurement and one representing a displacement which might readily be produced by a protrusion into the canal. Measurements were handicapped by a tendency to slight continued movement or "creep" after the initial displacement produced by various weights. Conversion of the actual forces into pressures was inaccurate since the surface of the dura and cord was curved and compressible and the exact area over which the forces were acting was not known. The hook width was $4 \mathrm{~mm}$. and for purposes of calculation it was assumed that its effective length was equal to the average adult diameter of the cord; a value two-thirds of the latter was taken for the 7-year-old subject. The results are therefore conservative. They refer to the pressures between the anterior dura and the anterior wall of the spinal canal and do not necessarily indicate those acting between the cord and the canal. Although cushioned by the anterior dural sheath, cord pressures are likely to be similar since the chief cause of tension appears to lie in the posterior dura. For displacements of 1 or $2 \mathrm{~mm}$. forces were much less; thus in Case 28 at level 
C7-8 weights were 12,16 , and $28 \mathrm{oz}$. for movements of 1,2 , and $3 \mathrm{~mm}$. respectively.

\section{Examination of Other Factors Tending to Produce Damage in Cervical Spondylosis}

This was done in three positions of the head and neck. In extension the canal could be seen to be narrowed from front to back, the ligamenta flava projected inwards, and small ridges were raised over each disc in the anterior wall. No difficulty was found in moving the cord and dura against the posterior wall of the canal and no tethering could be found in either roots, rootlets, or ligamenta denticulata. In normal posture the same findings were obtained. In flexion of the spine the cord was held forward by its own elasticity and by that of the dura, which appeared to be the greater of the two. The ligamenta denticulata appeared to lie in almost a coronal plane and the acute forward direction depicted by Kahn (1947) could not be verified as normal, although it could be partially reproduced by inserting a small dissector through the arch of the ligamenta and producing a sharp dorsal angulation of the cord. With the canal completely unroofed and the spine in normal posture, the dura and cord could indeed be shifted dorsally until nerve roots became taut, but this movement was beyond the normal limits of the posterior wall of the canal. The rootlets and ligamenta denticulata could similarly be tightened and each at about the same time.

\section{Discussion}

In a painstaking examination on four Rhesus monkeys, Smith (1956) showed, with radiographic measurements, that in flexion of the head and trunk from the fully extended position, the spinal cord moved towards the disc C4-5 from above downwards and from below upwards. Downward movements were up to a maximum of $1.6 \mathrm{~mm}$. at the first cervical segment and upward shift was maximal and up to $5.9 \mathrm{~mm}$. between discs T3-4 and T8-9. There was still $4 \mathrm{~mm}$. of upward movement at L4-5. Results for man obtained here are not entirely comparable; measurements have been relatively crude and to the nearest millimetre only, while flexion has been variable from case to case and no way of flexing the trunk was feasible except by flexing the hips also. However, if a comparison is made, using observations at flexion of head and neck from the normal erect position, maximum movement in man appears to occur more cephalically over the lowest cervical and the upper three thoracic vertebrae.
Smith also found that each segment of the cord $\bar{z}$ was stretched in proportion to the amount of $\stackrel{\mathbb{D}}{\stackrel{C}{\mathscr{C}}}$ flexion at the joint immediately ventral to it, being greatest in the lower cervical and upper thoracic $\subseteq$ segments, and up to $24 \%$ in amount. In the present ${ }^{\circ}$ investigation greatest stretch was found in approximately the same region with a maximum of $17.6 \%$ 的 and an average value of $10 \%$.

The importance of movement, stretch, and anterior pressure in the human cord is not yet defined. However, the wide range of up-and-down $\stackrel{5}{\rightarrow}$ movement, particularly in the lower cervical and upper thoracic regions, has at least a clear bearing $\underline{\underline{D}}$ on normal anatomical description. Any discussion $\frac{\bar{s}}{7}$ of root direction whether based on radiological, $\stackrel{\varnothing}{\unrhd}$ surgical, or pathological examination, must at the same time define the position of the head and neck $\rightarrow$ relative to the trunk.

From a pathological point of view, it would seem $\overrightarrow{\vec{\omega}}$ probable that important effects might be produced 9 in the cord by its movement, stretch, and compression, over and against the anterior wall of the? spinal canal and projections from it. These factors $N$ vary somewhat in their sites of maximum develope ment.

Movements are minimal at the $\mathrm{C5}$ root an greatest at roots $\mathrm{C} 8$ to $\mathrm{T} 5$ approximately, where the extent is such that two cord segments could readily damaged by a single protrusion. Harmf yl effects of movement have been previously poste lated by Spillane and Lloyd (1952) and by O'Connêㄱ (1956) and are likely to be greatest where the copi is stretched over a convexity thus exerting pressure. anteriorly. Sections of the spine showing maximum flexion kyphosis probably vary with age and with the general mobility of the vertebral column, but would appear in adults to lie in the upper thoracic and lower cervical region.

Stretch is greatest between roots $\mathrm{C} 2$ and $\mathrm{T} 1$. This $\stackrel{2}{\Rightarrow}$ might very well be a potent factor in increasing the damage of any pathological process within the cord substance by disrupting relationships between nerve cells and fibres and their delicate vessels. Normally, the stretching produced by lengthening of the spinal canal is distributed over a considerable length of cord and dura. Greatest flexion and greatest increase in length of spine occur in the cervical region but the stretch thus produced in the cord $\bigcirc$ involves not only cervical but also thoracic segments. However, should thoracic stretch be prevented or 윽 modified by fixation of dura to disc protrusions $D$ then the full effect of flexion must be borne by such length of cord as is isolated above the area N with adhesions. This probably accounts for the degeneration of cord found around the origin of thickened ligamenta denticulata by Bedford, 
Bosanquet, and Russell (1952) in a case with dural adhesions to the posterior common ligament. Degenerative changes were indeed considered to be due to traction on the ligamenta. It was claimed by Allen (1952) that one of the chief objects of surgical removal of bony spurs in cervical spondylosis was to restore soft tissue glide and that relief of symptoms was proportional to the movements regained. This may act by allowing a greater distribution of stretch. It may not be too speculative to enquire whether more extensive pathological changes in the lateral columns owe such localization to the stresses of up-and-down movements acting through the ligamenta denticulata.

Pressure against the anterior wall of the canal deserves further investigation. If longitudinal tension were equally distributed throughout the entire length of the cord and dura it would be possible to state in general terms that the anterior component of force would be proportional to the degree of convexity of the spine at any point. However, information on the degree of spinal curvature and changes in flexion at different levels and for different ages is not available apart from the statement that the maximum depth of the normal thoracic kyphus is at the sixth thoracic vertebra. Further, tension is not equally distributed, since the cervical dura may be much more taut in flexion than that at lower levels. Actual measurements are required. From the few observations made here it would seem that in normal posture and over a $3 \mathrm{~mm}$..projection into the canal, an anterior pressure of about $2 \mathrm{lb}$. to the square inch is exerted by the cord and dura. In flexion, pressures of 30 to $40 \mathrm{lb}$. per square inch may be obtained. Degenerative shortening of the spine or any factors tending to slacken the dura would reduce the pressures possible against osteophytes and this may account for the fact that symptoms of spondylosis present chiefly in middleaged groups (Clarke and Robinson, 1956) rather than increase steadily with age.

Not only may movements and pressure inflict direct trauma on the cord but, by interference with its blood supply, they may conceivably cause indirect damage. Intermittent spasm, mechanical occlusion, or thrombosis of the anterior spinal artery might well occur. Such mechanisms have been implicated, particularly in cervical spondylosis. Flattening and blanching of the cord in cervical flexion and obliteration of venous channels over spondylitic spurs were noted by Allen (1952). The pattern of pathological changes in cervical myelopathy with spondylosis was thought by Mair and Druckman (1953) to correlate with the distribution of the anterior spinal artery. Vascular factors were felt to be important by Brain (1954 and 1956) and by Logue (1952 and 1957) who suggested in effect that they could be the most important and final common mechanism causing damage from a variety of predisposing factors.

Nerve roots resemble the cord in that they also show movement and stretch, varying in different sections of the spine, and can be held against protrusions from the anterior wall of the canal. They are also affected by spinal movements which open and narrow the intervertebral foramina. In extension, as pointed out by Frykholm (1951), narrowing of the foramina may increase root pain when intraforaminal protrusions are present. Maximal flexionextension movements in the vertebral column occur from joints C2-3 to C6-7, according to data quoted by Smith (1956). Apposition of pedicles from osteoporosis and disc degeneration has been seen in the present dissections and would presumably also predispose to development of such symptoms.

Up-and-down movements of the roots are pivoted, as it were, from the region of the dorsal root ganglia and are of greatest amplitude medially at their origin from the cord dura. As shown in Figs. 3 and 4 they may ride over uncovertebral processes or other projections. Depending upon their original direction and proximity to the margins of their foramina, varying degrees of contact with pedicles can be produced. Should their course be ascending, then they may appear to be held up or hooked over the inferior pedicles in the lower cervical spine.

In Fig. 3 (in extension) roots $\mathrm{C} 6$ and 7 may be seen to run closely over the inferior pedicles, while in flexion (Fig. 4) they lie well away and towards the upper margins of the foramina. Lateral movements of a very small order are also produced by flexion of the neck when upward movement of the dura and cord produces tightening of roots and slight inward shift. More marked lateral movements, although not more than 1-2 mm. in extent in the cadaver, may be observed in the cervical roots on abduction of the arm at the shoulder or on pulling the arm downwards. The marked anterior direction of cervical roots and their increased tension with flexion of the neck make for firm contact in up-and-down movements over lateral spurs or protrusions. Knight (1955) felt that friction was the major cause of rhizalgia in cervical spondylosis. The effects of lateral and up-and-down movements of roots over or against pedicles, uncovertebral processes, osteophytic, or disc protrusions might well result in root-sleeve fibrosis as described by Frykholm. Should the major cervical contribution to the anterior spinal artery be involved, serious cord damage again could be envisaged (Fig. 5).

Among factors reported to predispose to root and cord damage in cervical spondylosis have been 


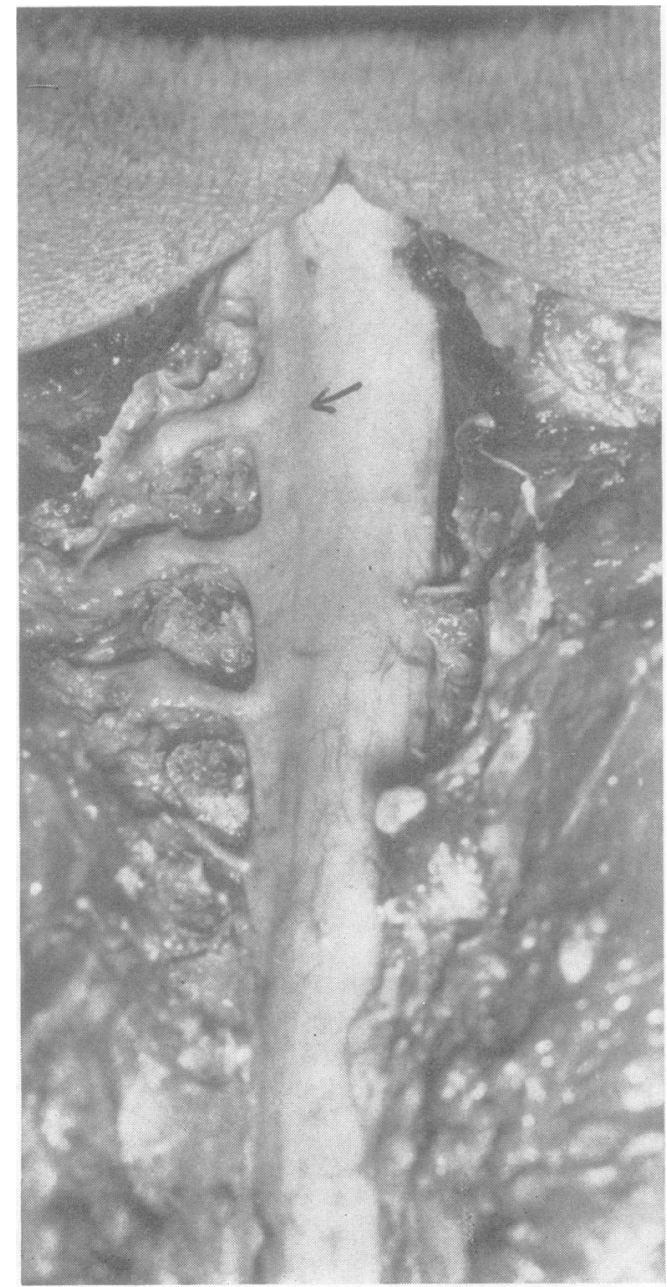

FIG. 3

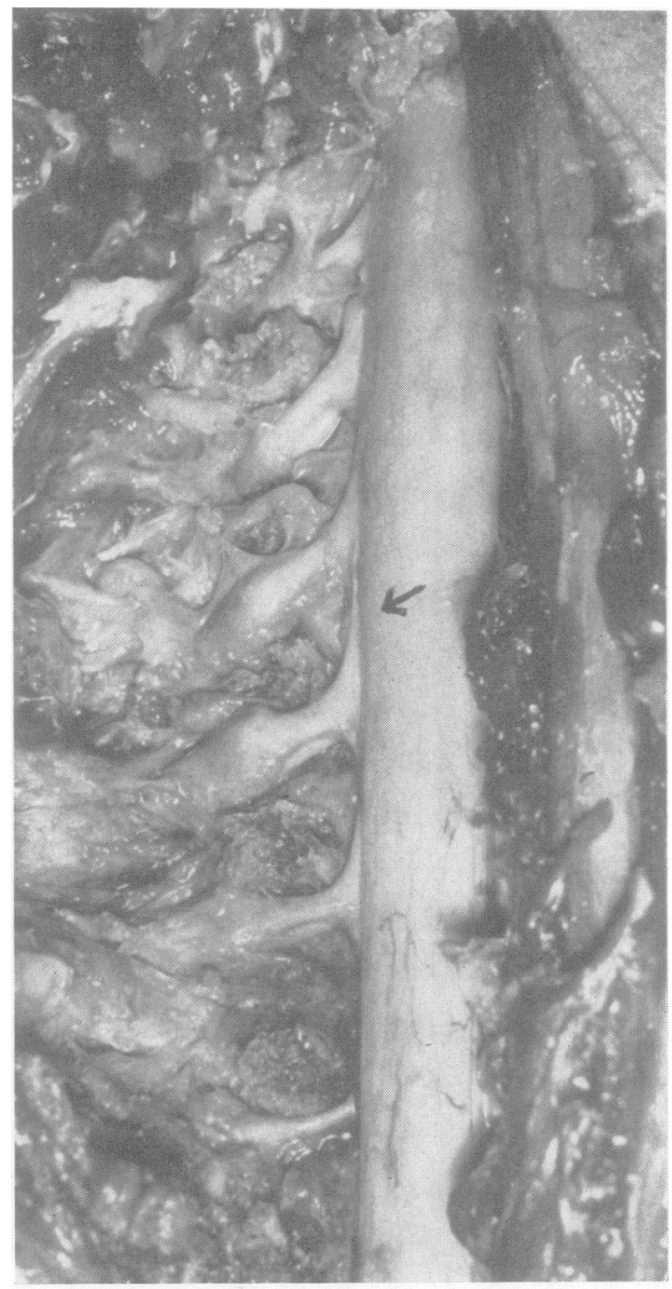

FIG. 4

Figs. 3 and 4.-Case 57, M., 54 years.

Ascending roots from $\mathrm{C} 8$ to $\mathrm{T} 10$ in normal posture. Fig. 3, in slight extension

The upward movement of dura and roots and altered relation to pedicles are well sh large osteophytic protrusion is seen. In extension this is covered by the root.

narrowing of the canal in extension (Symonds, 1953) or infolding of the ligamenta flava (Taylor, 1953) as well as congenital or spondylitic narrowing (Clarke and Little, 1955; Payne and Spillane, 1957). None of these can be questioned as real factors, although their general importance may be difficult to evaluate.

Other mechanisms holding the cord anteriorly in the canal, such as the tethering action of nerve roots and rootlets (O'Connell, 1956) or the ligamenta denticulata (Kahn, 1947), are less certain and the role of the ligamenta denticulata, although accepted by a number of writers, has been questioned by: Logue (1957) and by Bradshaw (1957). In theo present investigation their normal function has appeared to be the transmission of up-and-down? stresses between the cord and dura rather than pro- $\rightarrow$ viding a mechanism to hold the cord in any particular dorso-ventral position within the dura. Nor has any evidence been found to incriminate the roots as means whereby the cord is held forward. Rather it 0 is suggested that in flexion of the head and neck ${ }_{, 0}^{N}$ 


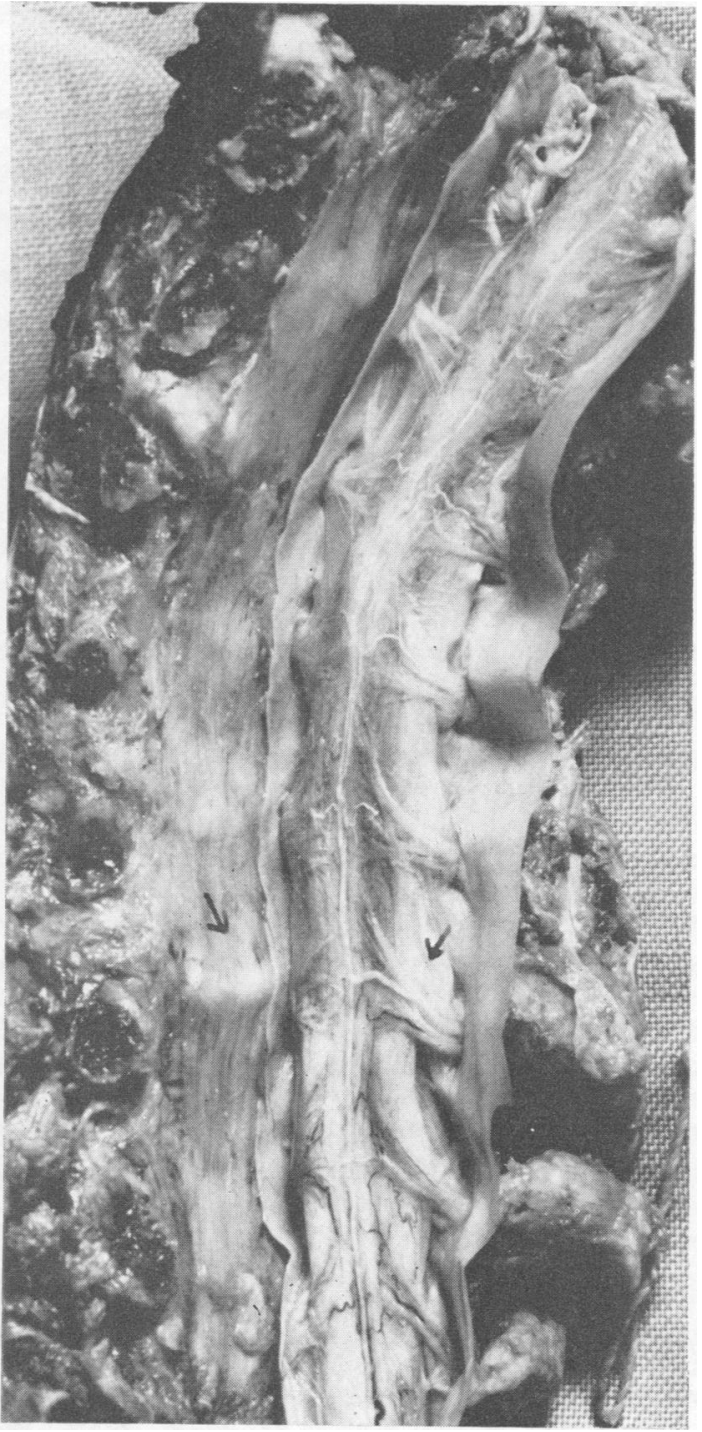

FIG. 5.-Excised cervical spine, illustrating the possibility of vascular damage in spondylosis. The major radicular contribution to the anterior spinal artery runs along the ventral rootlets of $\mathrm{C7}$ and lies directly over a prominent osteophytic ridge. Vessels were injected with barium via the vertebral arteries, before dissection, and the cord has been turned lover to the right side. Clinical diagnosis was amyotrophic lateral sclerosis with bulbar involvement. movements and stretch of cord and roots and the development of anterior components of force over a convex spine are likely to be more important factors in causing myelopathy and radiculitis. Conversely the absence of neurological changes in gross examples of spondylosis may be related to loss of spinal movements or to laxity of the dura, or to any combination of factors whereby stretching and anterior pressure on the cord are minimised.

\section{Summary}

Up-and-down movements of the spinal cord and dura were examined in flexion-extension movements of the head and spine. They were found to be of greatest extent and up to $1.8 \mathrm{~cm}$. in range at the levels of roots $\mathrm{C} 8$ to $\mathrm{T} 5$. In flexion the length of the spinal canal was increased and there was stretching of the cord and dura, chiefly between levels of roots $\mathrm{C} 2$ to $\mathrm{T} 1$, and up to a maximum of $17.6 \%$. An attempt was made to measure the anterior component of force exerted by the cord and dura under various degrees of tension. This was found to reach maximum values of 30 to $40 \mathrm{lb}$. per square inch for a displacement of $3 \mathrm{~mm}$. The effects produced in the cord and roots by movements, stretch, and pressure against the spinal canal and any projections within it were considered and thought probably to have significance in the production of myelopathy and radiculitis, particularly in cervical spondylosis.

\section{REFERENCES}

Allen, K. L. (1952). J. Neurol. Neurosurg. Psychiat., 15, 20. Bedford, P. D., Bosanquet, F. D., and Russell, W. Ritchie (1952). Lancet, 2, 55.

Bradshaw, P. (1957) Quart. J. Med. n.s., 26, 177.

Brain, R. (1954). Lancet, 1, 687

(1956). Proc. roy. Soc. Med., 49, 197.

Clarke, E., and Little, J. H. (1955). Neurology, 5, 861.

, and Robinson, P. K. (1956). Brain, 79, 483 .

Frykholm, R. (1951). Acta chir. scand., Suppl. 160.

Kahn, E. A. (1947). J. Neurosurg., 4, 191.

Knight, G. (1955). Proc. roy. Soc. Med., 48, 595.

Logue, V. (1952). J. Neurol. Neurosurg. Psychiat., 15, 227.

- (1957). In Modern Trends in Neurology (2nd series), ed. D. Williams, p. 259 . Butterworth, London.

Mair, W. G. P., and Druckman, R. (1953). Brain, 76, 70

O'Connell, J. E. A. (1956). Proc. roy. Soc. Med., 49, 202.

Payne, E. E., and Spillane, J. D. (1957). Brain, 80, 571.

Reid, J. D. (1958). N.Z. med. J., 57, 16.

- (1960). J. Neurol. Neurosurg. Psychiat., 23, 148.

Smith, C. G. (1956). Radiology, 66, 259.

Spillane, J. D., and Lloyd, G. H. T. (1952). Brain, 75, 177.

Symonds, Sir Charles (1953). Lancet, 1, 451.

Taylor, A. R. (1953). Ibid., 1, 717. 